\title{
Performance improvement using simple PID controller tuning formulae
}

Aidan O'Dwyer

Technological University Dublin, aidan.odwyer@tudublin.ie

Follow this and additional works at: https://arrow.tudublin.ie/engscheleart

Part of the Controls and Control Theory Commons

\section{Recommended Citation}

O'Dwyer, Aidan : Performance improvement using simple PID controller tuning formulae. Proceedings of the 3rd IET International Conference on Power Electronics, Machines and Drives (PEMD 2006), pp.

276-280, Dublin. doi:10.21427/ve0n-1b66

This Conference Paper is brought to you for free and open access by the School of Electrical and Electronic Engineering at ARROW@TU Dublin. It has been accepted for inclusion in Conference papers by an authorized administrator of ARROW@TU Dublin. For more information, please contact arrow.admin@tudublin.ie, aisling.coyne@tudublin.ie,gerard.connolly@tudublin.ie. 


\title{
Performance Improvement using Simple PID Controller Tuning Formulae
}

\author{
Aidan O'Dwyer \\ School of Control Systems and Electrical Engineering, Dublin Institute of Technology, Ireland. \\ E-mail: aidan.odwyer@dit.ie
}

Keywords: Control, PI, PID, tuning rules.

\begin{abstract}
The proportional integral derivative (PID) controller is the most dominant form of automatic controller in industrial use today. With this technique, it is necessary to adjust the controller parameters according to the nature of the process. Thus, for effective control of a HVDC system, for example, specific values need to be chosen for the $\mathrm{P}$, I and D parameters, which will be different for the values required to control, for example, an induction motor drive. This tailoring of controller to process is known as controller tuning. Controller tuning is easily and effectively performed using tuning rules (i.e. formulae for controller tuning, based on process information). Such tuning rules allow the easy set up of controllers to achieve optimum performance at commissioning. Importantly, they allow ease of recommissioning if the characteristics of the process change. The paper communicates the results of recent work in the collation of industry-relevant PI and PID controller tuning rules, which may be applied to a variety of applications in power electronics, machines and drives.
\end{abstract}

\section{Introduction}

PI and PID controllers have been at the heart of control engineering practice for seven decades. Historically, the first tuning rule for setting up controller parameters was defined in 1934 for the design of a proportional-derivative (PD) controller for a process exactly modelled by an integrator plus delay (IPD) model [3]. Subsequently, tuning rules were defined for PI and PID controllers, assuming the process was exactly modelled by a first order lag plus delay (FOLPD) model [4] or a pure delay model [4], [9].

In the wide area covered by power electronics, machines and drives, PI or PID controllers have been considered for the control of DC-DC converters (e.g. [1]), flexible AC transmission systems (e.g. [15]), synchronous machines (e.g. [6]), HVDC systems (e.g. [18]), electric vehicle speed (e.g. [14]) and induction motor servodrives (e.g. [13]). In general, at commissioning, the PID controller is installed and tuned. However, surveys indicating the state of industrial practice report sobering results. For example, in the testing of thousands of control loops, it has been found that $65 \%$ of loops operating in automatic mode produce less variance in manual than in automatic (i.e. the automatic controllers are poorly tuned) [8]. Process performance deteriorates when the controller is poorly tuned; this deterioration may be reflected, for example, in a reduction in energy efficiency and increased environmental emissions. The net effect will be an increase in operating costs and a reduction in overall competitiveness. However, good controller tuning, for example, can allow the recovery of up to $6 \%$ of energy costs, in a variety of industries [5].

Thus, there is strong evidence that PI and PID controllers remain poorly understood and, in particular, poorly tuned in many applications. This is surprising, as very many tuning rules exist to allow the specification of the controller parameters. Tuning rules have the advantage of ease of calculation of the controller parameters (when compared to more analytical controller design methods), on the one hand; on the other hand, the use of tuning rules is a good alternative to trial and error tuning. It is clear that the many controller tuning rules proposed in the literature are not having an impact on industrial practice. One reason is that the tuning rules are not very accessible, being scattered throughout the control literature; in addition, the notation used is not unified.

It is timely, therefore, to communicate the results of recent work done in the collation of tuning rules, using a unified notation, for continuous-time PI and PID control of singleinput, single-output (SISO) processes [16], [17]. Such rules may be specified for processes either without or with a time delay (dead-time) term; such terms arise in voltage source inverters, for example, where a dead-time is required to prevent a shorting condition during switching [12]. Generally, a dead-time term is common; sources of dead-time range from the finite time required for information transmission to application-specific issues, such as the dead time in a motor drive due to imperfect mechanical coupling [13].

Firstly, a brief summary of the range of PI and PID controller structures proposed in the literature, together with the process models used to define the controller tuning rules, is provided. Then, controller architecture and process modeling issues are outlined, followed by the outline of tuning rules for setting up PI and PID controllers, for a number of process models. Finally, conclusions to the paper are drawn. Due to space restrictions, a case study of the application of tuning rules to design a controller for a pilot-scale plant is detailed in the poster presentation accompanying this paper. 


\section{Controller architecture and process modeling}

A practical difficulty with PID control technology is a lack of industrial standards, which has resulted in a wide variety of PID controller architectures. Seven different structures for the PI controller and forty-six different structures for the PID controller have been identified. Controller manufacturers vary in their choice of architecture; controller tuning that works well on one architecture may work poorly on another. Full details are given in [16], [17]; considering the PID controller, common architectures are:

1. The 'ideal' PID controller (Figure 1), given by

$$
\mathrm{G}_{\mathrm{c}}(\mathrm{s})=\mathrm{K}_{\mathrm{c}}\left(1+\frac{1}{\mathrm{~T}_{\mathrm{i}} \mathrm{s}}+\mathrm{T}_{\mathrm{d}} \mathrm{s}\right)
$$

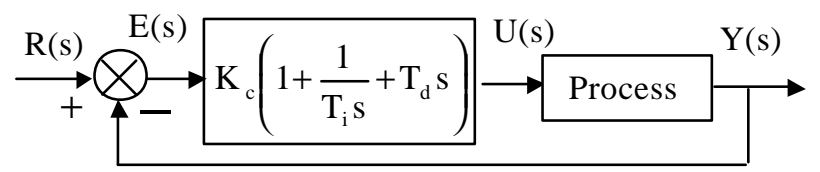

Figure 1. Ideal PID controller in a unity feedback block diagram representation. This controller structure, and an equivalent structure, is also labelled the parallel, ideal parallel, non-interacting, parallel noninteracting, independent, gain independent or ISA controller [17]. 276 tuning rules have been identified for this controller structure.

This architecture is used, for example, on the Honeywell TDC3000 Process Manager Type A, non-interactive mode product [11].

2. The 'classical' PID controller (Figure 2), given by

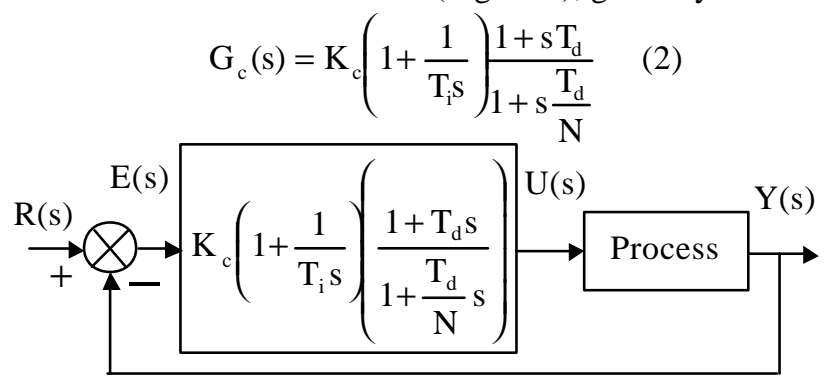

Figure 2. Classical PID controller in a unity feedback block diagram representation. Also labelled the cascade, interacting, series, interactive, rate-before-reset or analog controller [17], 101 tuning rules have been identified for this controller structure.

This architecture is used, for example, on the Honeywell TDC3000 Process Manager Type A, interactive mode product [11].

3. The non-interacting controller based on the two degree of freedom structure (Figure 3), given by

$\mathrm{U}(\mathrm{s})=\mathrm{K}_{\mathrm{c}}\left(1+\frac{1}{\mathrm{~T}_{\mathrm{i}} \mathrm{s}}+\frac{\mathrm{T}_{\mathrm{d}} \mathrm{s}}{1+\frac{\mathrm{T}_{\mathrm{d}}}{\mathrm{N}} \mathrm{s}}\right) \mathrm{E}(\mathrm{s})-\mathrm{K}_{\mathrm{c}}\left(\alpha+\frac{\beta \mathrm{T}_{\mathrm{d}} \mathrm{s}}{1+\frac{\mathrm{T}_{\mathrm{d}}}{\mathrm{N}} \mathrm{s}}\right) \mathrm{R}(\mathrm{s})$

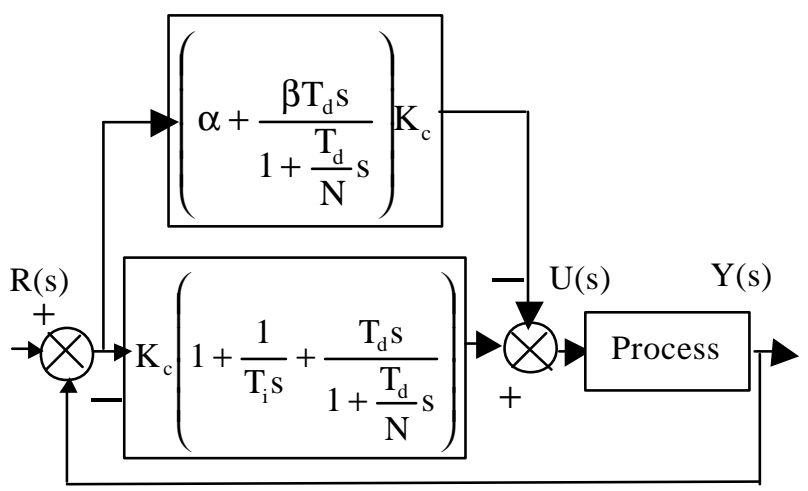

Figure 3. Non-interacting controller, based on the two degree of freedom structure, in a unity feedback block diagram representation. Also labelled the m-PID or ISA-PID controller [17], 44 tuning rules have been identified for this controller structure.

This architecture is used, for example, on the Omron E5CK digital controller with $\beta=1$ and $\mathrm{N}=3$ [11].

The most dominant PI controller architecture is the 'ideal' PI controller, given by

$$
\mathrm{G}_{\mathrm{c}}(\mathrm{s})=\mathrm{K}_{\mathrm{c}}\left(1+\frac{1}{\mathrm{~T}_{\mathrm{i}} \mathrm{s}}\right)
$$

The wide variety of controller architectures is mirrored by the wide variety of ways in which processes with time delay may be modeled. Common models are:

1. Stable FOLPD model, given by

$$
\mathrm{G}_{\mathrm{m}}(\mathrm{s})=\frac{\mathrm{K}_{\mathrm{m}} \mathrm{e}^{-\mathrm{s \tau _{ \textrm {m } }}}}{1+\mathrm{s} \mathrm{T}_{\mathrm{m}}}
$$

2. IPD model, given by

$$
\mathrm{G}_{\mathrm{m}}(\mathrm{s})=\frac{\mathrm{K}_{\mathrm{m}} \mathrm{e}^{-\mathrm{s \tau} \mathrm{m}}}{\mathrm{s}}
$$

3. First order lag plus integral plus delay (FOLIPD) model, given by

$$
\mathrm{G}_{\mathrm{m}}(\mathrm{s})=\frac{\mathrm{K}_{\mathrm{m}} \mathrm{e}^{-\mathrm{s \tau} \tau_{\mathrm{m}}}}{\mathrm{s}\left(1+\mathrm{s} \mathrm{T}_{\mathrm{m}}\right)}
$$

4. Second order system plus time delay (SOSPD) model, given by

$$
\begin{aligned}
& \mathrm{G}_{\mathrm{m}}(\mathrm{s})=\frac{\mathrm{K}_{\mathrm{m}} \mathrm{e}^{-\mathrm{s \tau} \tau_{\mathrm{m}}}}{\mathrm{T}_{\mathrm{m} 1}{ }^{2} \mathrm{~s}^{2}+2 \xi_{\mathrm{m}} \mathrm{T}_{\mathrm{ml}} \mathrm{s}+1} \\
& \text { or } \mathrm{G}_{\mathrm{m}}(\mathrm{s})=\frac{\mathrm{K}_{\mathrm{m}} \mathrm{e}^{-\mathrm{s \tau} \tau_{\mathrm{m}}}}{\left(1+\mathrm{T}_{\mathrm{m} 1} \mathrm{~s}\right)\left(1+\mathrm{T}_{\mathrm{m} 2} \mathrm{~s}\right)}
\end{aligned}
$$

Some $82 \%$ of the PI controller tuning rules identified have been defined for the ideal PI controller structure, with $42 \%$ of tuning rules based on a FOLPD process model. The range of PID controller variations has lead to a less homogenous situation than for the PI controller; $40 \%$ of tuning rules identified have been defined for the ideal PID controller structure, with $37 \%$ of PID tuning rules based on a FOLPD process model [17].

Of course, the modeling strategy used influences the value of the model parameters, which, in turn, affect the controller 
values determined from the tuning rules. Forty-one modeling strategies have been detailed to determine the parameters of the FOLPD process model, for example. Space does not permit a full discussion of this issue; further details are provided in [16], [17].

\section{Tuning Rules for PI and PID Controllers}

Before considering tuning rules for PI and PID controllers in more detail, it is timely to review the action of the PID controller. Consider the ideal PID controller, for example, which is given by

$$
\mathrm{G}_{\mathrm{c}}(\mathrm{s})=\mathrm{K}_{\mathrm{c}}\left(1+\frac{1}{\mathrm{~T}_{\mathrm{i}} \mathrm{s}}+\mathrm{T}_{\mathrm{d}} \mathrm{s}\right)
$$

with $\mathrm{K}_{\mathrm{c}}=$ proportional gain, $\mathrm{T}_{\mathrm{i}}=$ integral time constant and $\mathrm{T}_{\mathrm{d}}=$ derivative time constant. If $\mathrm{T}_{\mathrm{i}}=\infty$ and $\mathrm{T}_{\mathrm{d}}=0$ (that is, $\mathrm{P}$ control), then the closed loop measured value is always less than the desired value for processes without an integrator term, as a positive error is necessary to keep the measured value constant, and less than the desired value. The introduction of integral action facilitates the achievement of equality between the measured value and the desired value, as a constant error produces an increasing controller output. The introduction of derivative action means that changes in the desired value may be anticipated, and thus an appropriate correction may be added prior to the actual change. Thus, in simplified terms, the PID controller allows contributions from present, past and future controller inputs.

PI and PID controller tuning rules may be broadly classified as follows:

- Tuning rules based on a measured step response

- Tuning rules based on minimising an appropriate performance criterion

- Tuning rules that give a specified closed loop response

- Robust tuning rules, with an explicit robust stability and robust performance criterion built in to the design process

- $\quad$ Tuning rules based on recording appropriate parameters at the ultimate frequency.

Tuning rules in the first four subdivisions are typically based on process model parameters; the development of a process model is typically not required for using tuning rules in the final subdivision above. Some tuning rules could be considered to belong to more than one subdivision, so the subdivisions cannot be considered to be mutually exclusive; nevertheless, they provide a convenient way to classify the rules. An outline of tuning rules in these subdivisions is now provided.

Tuning rules based on a measured step response are also called process reaction curve methods. The first (and most well-known) tuning rule of this type was suggested in 1942 [20]; in this method, the process is modeled by a FOLPD process model with the model parameters estimated using a tangent and point method, as indicated in Figure 4. Simple formulae are used to define tuning parameters for PI and PID controllers. The PI controller settings are given by

$$
\mathrm{K}_{\mathrm{c}}=\frac{0.9 \mathrm{~T}_{\mathrm{m}}}{\mathrm{K}_{\mathrm{m}} \tau_{\mathrm{m}}}, \mathrm{T}_{\mathrm{i}}=3.33 \tau_{\mathrm{m}}
$$

The (ideal) PID controller settings are given by

$$
\mathrm{K}_{\mathrm{c}} \in\left[\frac{1.2 \mathrm{~T}_{\mathrm{m}}}{\mathrm{K}_{\mathrm{m}} \tau_{\mathrm{m}}}, \frac{2 \mathrm{~T}_{\mathrm{m}}}{\mathrm{K}_{\mathrm{m}} \tau_{\mathrm{m}}}\right], \mathrm{T}_{\mathrm{i}}=2 \tau_{\mathrm{m}}, \mathrm{T}_{\mathrm{d}}=0.5 \tau_{\mathrm{m}}
$$

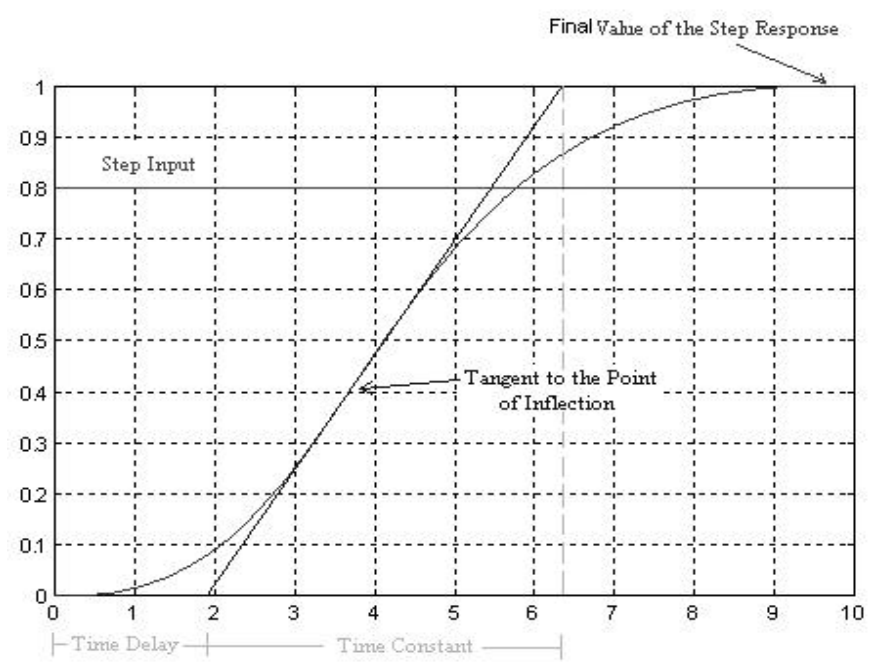

Figure 4. Tangent and point method [20] for developing a process model. $\mathrm{K}_{\mathrm{m}}=$ model gain = ratio of the steady state change in process output to steady state change in process input, $\mathrm{T}_{\mathrm{m}}=$ model time constant and $\tau_{\mathrm{m}}=$ model time delay. 54 controller tuning rules have been identified based on the model parameters determined from this modelling method. 21 of the 47 other modelling methods for determining such a process model, prior to specifying tuning rules, are based on data gathered from the open loop process step or impulse response [17].

Other process reaction curve tuning rules are also described, sometimes in graphical form, to control delayed processes represented by a variety of models [17]. The advantage of process reaction curve tuning strategies is that only a single experimental test is necessary. However, the disadvantages of the strategy are primarily based on the difficulty, in practice, of obtaining an accurate process model; for example, load changes may occur during the test which may distort the test results and a large step input may be necessary to achieve a good signal to noise ratio. Similar disadvantages arise in any tuning method dependent on prior model development.

Tuning rules based on minimising an appropriate performance criterion may be defined either for optimum regulator or optimum servo action. Performance criteria, such as the minimisation of the integral of absolute error (IAE) in a closed loop environment, may be used to determine a unique set of controller parameter values. Tuning rules have been described, sometimes in graphical form, to optimise the regulator response, servo response or other characteristics of a compensated delayed process, represented by a variety of models [17].

Tuning rules that give a specified closed loop response (direct synthesis tuning rules) may be defined by specifying a time domain related metric, such as the desired poles of the closed loop response. The definition may be expanded to cover techniques that allow the achievement of a frequency domain metric, such as a specified gain margin and/or phase margin. 
Tuning rules of this type have been specified to compensate a delayed process, represented by a variety of models [17].

Robust tuning rules have an explicit robust stability and/or robust performance criterion built in to the design process. Tuning rules of this type have also been specified to compensate a delayed process, represented by a variety of models [17].

Ultimate cycle tuning rules are based on recording appropriate parameters at the ultimate frequency (that is, the frequency at which marginal stability of the closed loop control system occurs). The first such tuning rule was defined in 1942 [20] for the tuning of P, PI and PID controller parameters of a process that may or may not include a delay. Briefly, the experimental technique is as follows:

a) Place the controller in proportional mode only

b) Increase $\mathrm{K}_{\mathrm{c}}$ until the closed loop system output goes marginally stable; record $\mathrm{K}_{\mathrm{c}}$ (calling it $\mathrm{K}_{\mathrm{u}}$, the ultimate gain), and the ultimate period, $\mathrm{T}_{\mathrm{u}}$; a typical marginally stable output, recorded on a laboratory flow process, is shown in Figure 5.

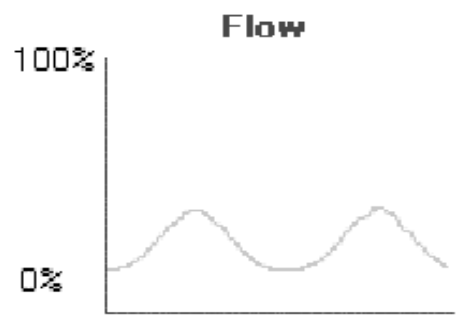

Figure 5. Typical marginally stable process variable pattern. Note that the pattern exhibits evidence of a process nonlinearity, which is common in real applications. Over 129 controller tuning rules have been defined, based on the data determined from such a pattern [17].

Simple formulae are used to define tuning parameters for PI and PID controllers. The PI controller settings are given by

$$
\mathrm{K}_{\mathrm{c}}=0.45 \mathrm{~K}_{\mathrm{u}}, \mathrm{T}_{\mathrm{i}}=0.83 \mathrm{~T}_{\mathrm{u}}
$$

with the (ideal) PID controller settings given by

$$
\mathrm{K}_{\mathrm{c}}=0.6 \mathrm{~K}_{\mathrm{u}}, \mathrm{T}_{\mathrm{i}}=0.5 \mathrm{~T}_{\mathrm{u}}, \mathrm{T}_{\mathrm{d}}=0.125 \mathrm{~T}_{\mathrm{u}}
$$

The tuning rules implicitly build an adequate frequency domain stability margin into the compensated system [7]. However, there are a number of disadvantages to the ultimate cycle tuning approach:

- the system must generally be destabilised under proportional control

- the empirical nature of the method means that uniform performance is not achieved in general [10]

- several trials must typically be made to determine the ultimate gain

- the resulting process upsets may be detrimental to product quality
- there is a danger of misinterpreting a limit cycle as representing the stability limit [19] and

- the amplitude of the process variable signal may be so great that the experiment may not be carried out for cost or safety considerations.

Some of these disadvantages are addressed by defining modifications of the rules in which, for example, the proportional gain in the experiment is set up to give a closed loop transient response decay ratio of 0.25 , or a phase lag of $135^{\circ}$. Ultimate cycle tuning rules, and their modifications, have been specified to compensate general, possibly delayed processes, represented by a variety of models [17].

\section{Conclusions}

Control academics and practitioners remain interested in the use of PI and PID controllers. PID controller tuning rules can be directly implemented in a variety of applications i.e. the hardware already exists, but it needs to be optimised. The outcome is directly measurable in, for example, energy savings and waste reduction (including greenhouse gas emission reduction). This paper summarises work carried out in tuning rule development. The most startling statistic to emerge from the work is the quantity of tuning rules identified to date; 443 PI tuning rules and 691 PID tuning rules, a total of 1134 separate rules. Recent years have seen an acceleration in the accumulation of tuning rules. In general, there is a lack of comparative analysis regarding the performance and robustness of closed loop systems compensated with controllers whose parameters are chosen using the tuning rules; associated with this is the lack of benchmark processes, at least until recently [2]. In addition, much work remains to be done in the evaluation of controllers designed using tuning rules in a wide variety of practical applications, including applications in power electronics, machines and drives. The main priority for future research in the area should be a critical analysis of available tuning rules, rather than the proposal of further tuning rules.

Historical note: The $70^{\text {th }}$ anniversary of the receipt of the first technical paper describing tuning rules for setting up controller parameters [4] is presently being marked. The paper was received by the Philosophical Transactions of the Royal Society of London on July 15, 1935; the paper was received, in revised form, on November 26, 1935 and was read on February 2, 1936. The lead author of the paper subsequently took out a patent on the PID controller (Callender, A. and Stevenson, A.B., Automatic control of variable physical characteristics, US patent 2,175,985. Filed: Feb. 17, 1936; Issued Oct. 10, 1939).

\section{References}

[1] J. Alvarez-Ramirez, I. Cervantes, G. Espinosa-Perez, P. Maya and A. Morales. "A stable design of PI control for DC-DC converters with a RHS zero", IEEE Transactions on Circuits and Systems - I: Fundamental Theory and Applications, 46, pp. 103-106, (2000). 
[2] K.J. Åström and T. Hägglund. "Benchmark systems for PID control", Preprints Proc. PID '00: IFAC Workshop, pp. 181-182, (2000).

[3] A. Callendar. "Preliminary notes on automatic control", I.C.I. Alkali Ltd., Northwich, U.K., Central File No. R.525/15/3 (1934).

[4] A. Callendar, D.R. Hartree, and A. Porter. "Time-lag in a control system", Phil. Trans. Royal Society of London Series A, 235, pp. 415-444, (1935/6).

[5] Case histories accompanying Good Practice Guide 346 (Improving the effectiveness of basic closed loop control systems), The Carbon Trust (www.thecarbontrust.co.uk).

[6] H.R. De Azevedo and K.P. Wong. "A fuzzy logic controller for permanent magnet synchronous machine a sliding mode approach", Proceedings of the IEEE Power Conversion Conference, pp. 672-677, (1993).

[7] A.M. De Paor. "A fiftieth anniversary celebration of the Ziegler-Nichols PID controller”, Int. J. Elect. Eng. Education, 30, pp. 303-316, (1993).

[8] D.B. Ender. "Process control performance: not at good as you think", Control Engineering, September, pp. 180-190, (1993).

[9] D.R. Hartree, A. Porter, A. Callender and A.B. Stevenson. "Time-lag in a control system - II", Proc. Royal Society of London, 161(A), pp. 460-476, (1937).

[10] S.-H. Hwang and T.-S. Tseng. "Process identification and control based on dominant pole expansions", Chem. Eng. Sci., 49, pp. 1973-1983, (1994).

[11] ISMC. RAPID: Robust Advanced PID Control Manual. Intelligent System Modeling and Control nv, Belgium, (1999).

[12] J. Jung and K. Nam. "A PI-type dead-time compensation method for vector-controlled GTO inverters", IEEE Transactions on Industry Applications, 34, pp. 452-457 (1998).

[13] F.J. Lin, C.M. Liaw, Y.S. Shieh, R.J. Guey and M.S. Hwang. "Robust two-degrees-of-freedom control for induction motor servodrives", IEE Proc.-Electr. Power Appl., 142, pp. 79-86, (1995).

[14] S. Matsumura, S. Omatu and H. Higasa. "Improvement of speed control performance using PID type neurocontroller in an electric vehicle system", Proceedings of the IEEE World Congress on Computational Intelligence, 4, pp. 2649-2654, (1994).

[15] S. Morris, P.K. Dash and K.P. Basu. "A fuzzy variable structure current controller for flexible AC transmission systems", Proceedings of the IEEE Transmission and Distribution Conference and Exhibition, 1, pp. 330-335, (2002).

[16] A. O'Dwyer. Handbook of PI and PID controller tuning rules. London, U.K.: Imperial College Press, (2003).

[17] A. O'Dwyer. Handbook of PI and PID controller tuning rules (Edition 2). London, U.K.: to be published by Imperial College Press, (2006).

[18] K.R. Padiyar and N. Prabhu. "Modelling, control design and analysis of VSC based HVDC transmission systems", Proceedings of the International Conference on Power Systems Technology, pp. 774-779, (2004).
[19] D.W. Pessen. "A new look at PID-controller tuning", Trans. ASME. J. Dyn. Sys., Meas. Control, 116, pp. 553557, (1994).

[20] J.G. Ziegler and N.B. Nichols. "Optimum settings for automatic controllers", Trans. ASME, 64, pp. 759-768, (1942). 